\title{
Antibiotic use and resistance: Knowledge, attitudes and perceptions among primary care prescribers in South Africa
}

\author{
E Farley, ${ }^{1} \mathrm{MPH}$; A Stewart, ${ }^{2} \mathrm{MPH}$; M-A Davies, ${ }^{1,3} \mathrm{PhD}, \mathrm{MPH}, \mathrm{MB} \mathrm{ChB}$; M Govind, ${ }^{4} \mathrm{MB} \mathrm{ChB}$; \\ D van den Bergh, ${ }^{5,6}$ EngD, MSc (Med), BPharm; T H Boyles, ${ }^{6}$ MA, BM, BCh, MCRP, MD, DTM\&H, Cert ID (SA) \\ ${ }^{1}$ Department of Public Health and Family Medicine, Faculty of Health Sciences, University of Cape Town, South Africa \\ ${ }^{2}$ Clinical Research Centre, Faculty of Health Sciences, University of Cape Town, South Africa \\ ${ }^{3}$ Centre for Infectious Disease Epidemiology and Research, Faculty of Health Sciences, University of Cape Town, South Africa \\ ${ }^{4}$ Independent Practitioners Association Foundation, Johannesburg, South Africa \\ ${ }^{5}$ Department of Quality Systems and Innovation, Netcare Hospitals Ltd, Johannesburg, South Africa \\ ${ }^{6}$ Division of Infectious Diseases and HIV Medicine, Department of Medicine, Faculty of Health Sciences, University of Cape Town, South Africa
}

Corresponding author: E Farley (elisefarley@gmail.com)

Background. Antibiotic resistance (ABR) is a major threat to global health, driven in part by inappropriate prescription of antibiotics in primary care.

Objectives. To describe South African (SA) prescribers' knowledge of, attitudes to and perceptions of ABR.

Methods. We conducted a cross-sectional survey of knowledge of, attitudes to and perceptions of ABR among a convenience sample of primary healthcare providers in SA, the majority from the private sector. We used logistic regression to examine associations between knowledge and prescribing behaviours.

Results. Of 264 prescriber respondents, 95.8\% (230/240) believed that ABR is a significant problem in SA and 66.5\% (157/236) felt pressure from patients to prescribe antibiotics. The median knowledge score was $5 / 7$, and scores were highest in respondents aged $<55$ years $(p=0.0001)$. Prescribers with higher knowledge scores were more likely than those with lower scores to believe that to decrease ABR, narrowspectrum antibiotics should be used (adjusted odds ratio (aOR) 1.29, 95\% confidence interval (CI) 1 - 1.65) and more likely to report that explaining disease features that should prompt follow-up was a useful alternative to prescribing (aOR 1.47, 95\% CI 1.058 - 2.04), and were less likely to report that antibiotics cannot harm the patient if they are not needed, so they prescribe when not necessary (aOR $0.57,95 \%$ CI $0.38-0.84)$.

Conclusions. Prescribers of antibiotics in the private sector in SA were aware of the problem of ABR, but felt pressure from patients to prescribe. Those with higher knowledge scores reported positive prescribing behaviours, suggesting that more education is needed to tackle the problem of ABR.

S Afr Med J 2018;108(9):763-771. DOI:10.7196/SAMJ.2018.v108i9.12933

Antibiotic resistance (ABR) is an established threat to global health. It is estimated that 700000 people die annually as a result of ABR, and this figure is set to rise to 10 million by 2050 if no action is taken. ${ }^{[1]}$ Inappropriate prescribing behaviours by clinicians have been implicated as a major contributing factor driving ABR worldwide, ${ }^{[2]}$ while the judicious use of antibiotics may delay the emergence of resistant bacteria and possibly facilitate a return of susceptible strains. Antibiotic stewardship (AS), which includes measures to reduce inappropriate antibiotic prescribing, is a key intervention to improve prescribing practices in ambulatory care ${ }^{[3]}$ and AS programmes have been shown to reduce the incidence of infection and colonisation with antibiotic-resistant bacteria. ${ }^{[4]}$

Antibiotic prescription usually involves an individual consultation between a patient and a clinician, so individual clinician prescribing behaviour is critical. Psychological theories illustrate that clinicians' knowledge and beliefs influence this process. ${ }^{[5]}$ Specifically, disease knowledge, beliefs about the consequences of prescribing decisions and perceived patient expectations all influence decision-making at clinical consultations. ${ }^{[6]}$

Numerous studies have assessed clinicians' knowledge of and beliefs about ABR, with a recent systematic review identifying 57 studies. ${ }^{[7]}$ However, the majority of studies have been conducted in high-resource settings, and only three studies were identified from Africa and one from South Africa (SA).

\section{Objectives}

To determine knowledge of, attitudes to and perceptions of ABR among primary care prescribers in SA.

\section{Methods}

From October 2015 to December 2016, we conducted a crosssectional survey of primary care prescribers in SA using a 14-point self-administered questionnaire. The questionnaire (Appendix 1) recorded basic demographic information, perceptions of antibiotic use and resistance and sources of current education about antibiotic use. Knowledge about antibiotic use was tested by seven multiplechoice questions. The structure and content of the survey were based on those used in previously conducted studies ${ }^{[7]}$ and adapted for our setting after discussion with infectious disease specialists and general practitioners (GPs). Depending on the category, there were either single or multiple answer responses such as agree/disagree/unsure or often/sometimes/never.

A convenience sampling approach was used. GPs were invited by Medicross (a primary care provider that manages 92 medical and 
dental centres across SA) management to participate in the survey following initial consultation with regional GP representatives. An email with a link to a SurveyMonkey (https://www.surveymonkey. com; SurveyMonkey Inc., USA) questionnaire was distributed to all Medicross facilities and two reminders were sent out during the course of the study. Paper questionnaires were also distributed to GPs at three conferences held between December 2015 and December 2016. Each conference was attended by $\sim 250$ GPs. Questionnaires were mostly completed at the conference, with the remainder returned by email within 2 weeks.

\section{Ethics approval}

Ethics approval for the study was obtained from the University of Cape Town Human Ethics Research Committee (ref. no. 722/2016).

\section{Data analysis}

A descriptive analysis was completed, and knowledge scores were calculated out of the number of questions answered by each participant. Knowledge scores for prescribers were skewed, so medians and interquartile ranges (IQRs) are reported. Prescribers' self-reported frequency of prescribing antibiotics was tested for association with knowledge scores using the Kruskal-Wallis test. Associations between knowledge scores and beliefs and behaviours were tested using Wilcoxon rank-sum tests and explored using logistic regression models. Analysis was conducted using Stata 14 (StataCorp, USA).

\section{Results}

\section{Study population}

A total of 264 prescribers completed the survey. Their demographics are shown in Table 1: 154/244 (63.1\%) were aged $>45$ years (20.9\% aged 45 - 55 and $42.2 \%$ aged $>55), 238 / 242$ (98.3\%) were doctors, and the majority $(207 / 244,84.8 \%)$ practised exclusively in the private sector.

\section{Attitudes and perceptions}

Fig. 1 illustrates specific prescriber beliefs. Of the prescribers, $97.1 \%$ (234/241) believed that antibiotics are overused in SA, 95.8\% (230/240) believed that ABR is a big problem in SA, and 66.5\% (157/236) felt pressure from patients to prescribe antibiotics; $29.6 \%$ (75/253) would prescribe antibiotics half of the time if a patient expected an antibiotic but the prescriber did not think it is necessary, while $48.0 \%(118 / 246)$ thought that other doctors often (over $70 \%$ of the time) prescribed antibiotics when they are not absolutely necessary. When respondents had prescribed antibiotics that were not necessary, the main reasons were pressure from patients $(n=108,40.9 \%)$ and that the patients could not afford laboratory tests $(n=107,40.5 \%)$.

\section{Educational resources}

Many prescribers $(210 / 240,87.5 \%)$ wanted more education on the appropriate use of antibiotics, $38.7 \%(91 / 235)$ used guidelines to guide prescription behaviours, and $28.6 \%$ (67/234) relied on tablets and smartphones and $27.6 \%(66 / 239)$ on academic journals. The majority $(226 / 235,96.2 \%)$ requested data on local resistance patterns, and $90.4 \%(208 / 230)$ requested education resource aids for discussions on ABR with patients. Prescribers stated that they would value clearer guidelines to improve their antibiotic prescribing in hard copy $(80.2 \%)$, on smart phone apps $(79.7 \%)$ or on interactive internet platforms (74.7\%).

\section{Knowledge}

The median knowledge score for prescribers was 5 (out of a maximum of 7, IQR 4-6) (Fig. 2). All the questions were correctly answered by 53 prescribers $(20.1 \%)$, and one prescriber $(0.4 \%)$ answered all the questions incorrectly. Prescribers aged $>55$ years had

\begin{tabular}{ll}
\multicolumn{2}{l}{ Table 1. Demographic characteristics of prescribers $(\mathrm{N}=\mathbf{2 6 4})$} \\
\hline Category & $\boldsymbol{n}(\mathbf{\%})^{*}$ \\
\hline Age (years) & $21 / 244(8.6)$ \\
$25-34$ & $69 / 244(28.3)$ \\
$35-44$ & $51 / 244(20.9)$ \\
$45-54$ & $103 / 244(42.2)$ \\
$\geq 55$ & 20 \\
Missing & \\
Profession & $4 / 242(1.7)$ \\
Nurse & $238 / 242(98.3)$ \\
Doctor & 22 \\
Missing & \\
Practice type & $10 / 244(4.1)$ \\
Public sector & $207 / 244(84.8)$ \\
Private sector & $15 / 244(6.1)$ \\
Both, mainly public & $12 / 244(4.9)$ \\
Both, mainly private & 20 \\
Missing & \\
*Percentages calculated on number of responses, not total sample size. &
\end{tabular}

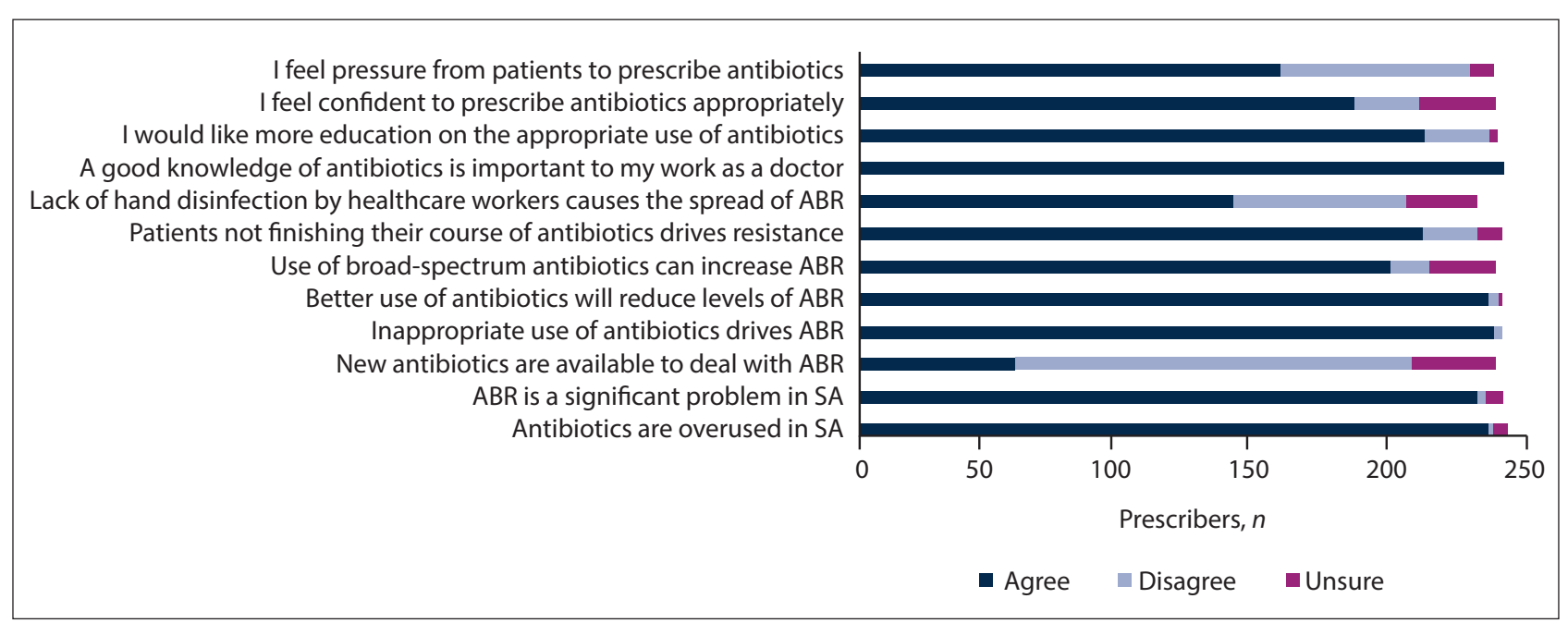

Fig. 1. Prescriber beliefs $(\mathrm{N}=264) .(A B R=$ antibiotic resistance; $S A=$ South $A$ frica. $)$ 
a lower median knowledge score (4.6, IQR 3.5 - 5.8) than younger prescribers (5.8, IQR $4.6-7 ; p=0.0001$ ) (Table 2).

Self-reported prescribing of antibiotics when not necessary was associated with lower knowledge scores $(p=0.005)$ (Table 3 ).

Several prescribing behaviours and beliefs were associated with increased knowledge scores. After adjusting for age and type of practitioner (nurse or doctor), a 1-unit increase in knowledge score was associated with an increase in odds of believing that narrowspectrum antibiotics should be used instead of broad-spectrum antibiotics where possible (adjusted odds ratio (aOR) 1.29, 95\% confidence interval (CI) 1 - 1.65), that explaining to patients features that, if they develop, should prompt them to seek further medical assistance when antibiotics are not necessary (aOR 1.47, 95\% CI $1.058-2.04$ ), and that explaining what to expect with regard to

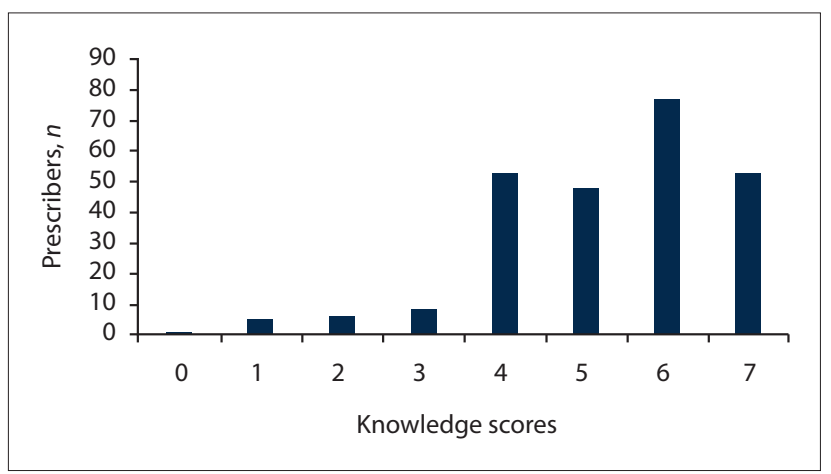

Fig. 2. Prescriber knowledge scores (maximum 7). duration of symptoms (aOR 122, 95\% CI 0.98 - 1.52) were alternative strategies to use instead of prescribing. Those with higher knowledge scores were less likely to report that antibiotics cannot harm the patient if they are not needed, so they prescribe when not necessary (aOR $0.57,95 \%$ CI $0.38-0.84 ; p=0.006$ ) (Table 4 ).

\section{Discussion}

Our study shows that $97.1 \%$ of primary care prescribers believe that antibiotics are overused in SA, while $95.8 \%$ believe that ABR is a significant problem and $66.5 \%$ feel pressure from patients to prescribe antibiotics. We found that knowledge scores among prescribers were suboptimal (median 5/7) and were highest in younger respondents. A novel finding is that knowledge scores are associated with prescribing behaviours. Higher knowledge scores were associated with using narrow-spectrum antibiotics, understanding the potential harm antibiotics can cause, trying alternative strategies such as explaining to patients the disease features that should prompt follow-up, and explaining duration of symptoms.

Our results are consistent with the findings of a large systematic review of clinicians' knowledge and beliefs about ABR. ${ }^{[7]}$ Similarities include prescribers feeling that ABR is a significant problem $(87 \%$ compared with 95.8\%), and that prescribers feel ABR is driven by patient non-adherence (96\% compared with $87.4 \%$ ) and excessive use (99\% compared with $97.1 \%$ ). ${ }^{[7,8]}$ Our study showed that $66.5 \%$ of prescribers felt pressure from patients to prescribe antibiotics, which is similar to an Australian-based study in which $37 \%$ of respondents stated they would prescribe antibiotics to meet a patient's expectations, ${ }^{[9]}$ and a qualitative study which showed that

Table 2. Association between prescriber knowledge scores and demographic characteristics (Wilcoxon rank-sum test) $(N=264)$

\begin{tabular}{|c|c|c|c|c|}
\hline \multirow[b]{2}{*}{ Category } & \multirow[b]{2}{*}{$n(\%)^{*}$} & \multicolumn{2}{|c|}{ Knowledge score (max. 7) } & \multirow[b]{2}{*}{$p$-value } \\
\hline & & Median & IQR & \\
\hline \multicolumn{5}{|l|}{ Age (years) } \\
\hline$<55$ & $141 / 244(57.8)$ & 5.8 & $4.6-7$ & 0.0001 \\
\hline$\geq 55$ & $103 / 244(42.2)$ & 4.6 & $3.5-5.8$ & \\
\hline Missing & 20 & & & \\
\hline \multicolumn{5}{|l|}{ Practitioner } \\
\hline Doctor & $238(98.3)$ & 5.6 & $4.2-6$ & 0.54 \\
\hline Nurse & $4(1.7)$ & 4.7 & $3.5-6$ & \\
\hline Missing & 22 & & & \\
\hline \multicolumn{5}{|c|}{ No. of consultations per day } \\
\hline$<24$ & $46(47.4)$ & 5 & $4.6-6$ & 0.89 \\
\hline$\geq 24$ & $51(52.6)$ & 5 & $4-7$ & \\
\hline Missing & 167 & & & \\
\hline
\end{tabular}

Table 3. Median knowledge scores for self-reported likelihood of prescribing antibiotics when not absolutely necessary (Kruskal-Wallis test)

\begin{tabular}{|c|c|c|c|c|}
\hline & \multirow[b]{2}{*}{$n(\%)^{*}$} & \multicolumn{2}{|c|}{ Knowledge score } & \multirow[b]{2}{*}{$p$-value } \\
\hline & & Median & IQR & \\
\hline Proportion of times prescribed antibiotics when not necessary & & & & 0.005 \\
\hline Very often $(>90 \%)$ & $5 / 253(2.0)$ & 3 & $3-5$ & \\
\hline Often $(>70 \%)$ & $15 / 253(5.9)$ & 4 & $2-4$ & \\
\hline About half the time $(50 \%)$ & $75 / 253(29.6)$ & 5 & $3-5$ & \\
\hline Rarely $(<30 \%)$ & $96 / 253(37.9)$ & 4 & $3-5$ & \\
\hline Almost never $(<10 \%)$ & $62 / 253(24.5)$ & 5 & $4-6$ & \\
\hline Missing & 11 & & & \\
\hline
\end{tabular}




\section{Table 4. Association between prescriber knowledge scores and attitudes and perceptions}

\begin{tabular}{|c|c|c|c|}
\hline Outcome (behaviour/perception) & $\begin{array}{l}\text { Adjusted } \mathrm{OR}^{*} \text { for } 1 \text { unit } \\
\text { increase in knowledge score }\end{array}$ & 95\% CI & $p$-value \\
\hline \multicolumn{4}{|l|}{ Antibiotics are overused in SA } \\
\hline Agree & 1.15 & $0.809-1.63$ & 0.44 \\
\hline \multicolumn{4}{|l|}{$A B R$ is a significant problem in $S A$} \\
\hline Agree & 1.34 & $0.88-2.026$ & 0.16 \\
\hline \multicolumn{4}{|c|}{ Lack of hand disinfection by healthcare } \\
\hline \multicolumn{4}{|l|}{ workers causes the spread of ABR } \\
\hline Agree & 1.093 & $0.89-1.34$ & 0.38 \\
\hline \multicolumn{4}{|c|}{ I would like more education on the appropriate } \\
\hline \multicolumn{4}{|c|}{ use of antibiotics } \\
\hline Agree & 1.14 & $0.86-1.51$ & 0.38 \\
\hline \multicolumn{4}{|c|}{ I feel pressure from patients to prescribe antibiotics } \\
\hline Agree & 0.93 & $0.75-1.15$ & 0.5 \\
\hline \multicolumn{4}{|c|}{$\begin{array}{l}\text { The patient expects an antibiotic, so I prescribe even } \\
\text { when unnecessary }\end{array}$} \\
\hline Agree & 0.92 & $0.76-1.1$ & 0.37 \\
\hline \multicolumn{4}{|c|}{$\begin{array}{l}\text { I think other doctors often prescribe antibiotics when } \\
\text { they are not necessary }\end{array}$} \\
\hline Agree & 0.905 & $0.75-1.095$ & 0.307 \\
\hline \multicolumn{4}{|c|}{ Better use of antibiotics will reduce levels of $A B R$} \\
\hline Agree & 1.55 & $0.9-2.65$ & 0.1 \\
\hline \multicolumn{4}{|c|}{$\begin{array}{l}\text { To decrease ABR, narrow-spectrum antibiotics should be } \\
\text { used instead of broad-spectrum antibiotics where possible }\end{array}$} \\
\hline Agree & 1.29 & $1-1.65$ & 0.045 \\
\hline \multicolumn{4}{|c|}{ I feel confident to prescribe antibiotics appropriately } \\
\hline Agree & 0.94 & $0.74-1.19$ & 0.62 \\
\hline \multicolumn{4}{|c|}{$\begin{array}{l}\text { Antibiotics don't need to be absolutely necessary, I just need to } \\
\text { think they may help the patient so I prescribe when not necessary }\end{array}$} \\
\hline Agree & 0.84 & $0.66-1.06$ & 0.15 \\
\hline \multicolumn{4}{|c|}{ Antibiotics can't harm the patient if they aren't needed so } \\
\hline \multicolumn{4}{|l|}{ I prescribe when not necessary } \\
\hline Agree & 0.57 & $0.38-0.84$ & 0.006 \\
\hline \multicolumn{4}{|c|}{$\begin{array}{l}\text { I'm concerned about malpractice claims so I prescribe } \\
\text { when not necessary }\end{array}$} \\
\hline Agree & 0.92 & $0.74-1.17$ & 0.52 \\
\hline \multicolumn{4}{|c|}{ I only prescribe antibiotics when absolutely necessary } \\
\hline Agree & 0.98 & $0.8-1.18$ & 0.82 \\
\hline \multicolumn{4}{|c|}{$\begin{array}{l}\text { More resources to educate patients: I would value more resources } \\
\text { to educate patients to improve my antibiotic prescribing }\end{array}$} \\
\hline Agree & 1.28 & $0.95-1.72$ & 0.11 \\
\hline \multicolumn{4}{|c|}{$\begin{array}{l}\text { More data on local ABR: I would value the following resources } \\
\text { to improve my antibiotic prescribing }\end{array}$} \\
\hline Agree & 1.13 & $0.701-1.82$ & 0.61 \\
\hline \multicolumn{4}{|c|}{$\begin{array}{l}\text { When antibiotics are not necessary, I explain what to expect } \\
\text { in terms of duration of symptoms }\end{array}$} \\
\hline Often & 1.22 & $0.98-1.52$ & 0.07 \\
\hline \multicolumn{4}{|c|}{$\begin{array}{l}\text { When antibiotics are not necessary, I explain features that, if } \\
\text { they develop, should prompt the patient to seek further medical assistance }\end{array}$} \\
\hline Often & 1.47 & $1.058-2.04$ & 0.02 \\
\hline \multicolumn{4}{|c|}{$\begin{array}{l}\text { When antibiotics are not necessary, I give written information } \\
\text { about why antibiotics would not help and may cause harm }\end{array}$} \\
\hline Often & 0.75 & $0.54-1$ & 0.09 \\
\hline \multicolumn{4}{|c|}{$\begin{array}{l}\text { When antibiotics are not necessary, I give written information } \\
\text { about what to expect in terms of symptom resolution }\end{array}$} \\
\hline Often & 0.74 & $0.54-1.01$ & 0.06 \\
\hline \multicolumn{4}{|c|}{ When antibiotics are not necessary, I prescribe symptomatic relief } \\
\hline Often & 1.05 & $0.83-1.35$ & 0.64 \\
\hline
\end{tabular}


prescriptions were often given to maintain good relationships with patients. ${ }^{[10]}$ An SA study showed that patients' expectations of antibiotics are strongly associated with prescribing behaviours ${ }^{[11]}$ and demonstrated that patients who are aware of the dangers of ABR expect antibiotics significantly less than those who are not.

A potential reason for older prescribers having lower knowledge scores could be lack of teaching on ABR at the time of their undergraduate medical training compared with more recent graduates. However, a recent study found that only $33 \%$ of final-year medical students in SA felt confident to prescribe antibiotics, and $95 \%$ stated they would like more information on appropriate use of antibiotics, suggesting that improvements in undergraduate training in $\mathrm{ABR}$ are required. ${ }^{[12]}$

The finding that knowledge scores are associated with positive prescribing behaviours suggests that improved education and training is likely to be an important intervention to address ABR in primary care prescribers. Many prescribers $(n=210,87.5 \%)$ wished to have more education on the appropriate use of antibiotics and would value clearer guidelines to improve their antibiotic prescribing in hard copy $(80.2 \%)$, on smart phone apps $(79.7 \%)$ or on interactive internet platforms (74.7\%). Respondents in a similar study who used guidelines scored higher on knowledge scores compared with those who did not use guidelines. ${ }^{[12]}$ There are therefore multiple media that could be used to provide education. Our findings suggest that intervention strategies could focus on prescribers in the over-55 age group, and efforts should focus on patient education and patientprescriber relationships to try to minimise the pressure placed on prescribers to prescribe when not necessary.

Interventions can include developing communication aids for prescriber/patient interactions, as $90.4 \%$ of prescribers requested education resource aids for discussions on ABR with patients. This would assist with issues of confusion when explaining the difference between viral and bacterial infections that have arisen in similar studies. ${ }^{[10]}$ The majority (96.2\%) of prescribers requested data on local resistance patterns, which opens up an opportunity to improve prescribing by introducing systems to supply up-to-date data on these. Educational programmes for prescribers have been shown to be successful in a range of settings ${ }^{[13]}$ and could be an effective intervention in SA. Further research on the most effective tools should be conducted, and proven methods should then be implemented. These suggestions show useful pathways that could be used to educate both patients and prescribers on the damage that can be caused by overprescription, and on the ABR crisis. Interventions should focus on increasing knowledge about $\mathrm{ABR}$, which could then have an impact on the attitudes, perceptions and behaviours of prescribers.

\section{Study limitations}

Our study has several limitations, some of which may limit its generalisability. The use of convenience sampling may have introduced selection bias in favour of prescribers who were more interested in ABR and felt more confident in their knowledge. This is likely to have led to an over-estimate of true knowledge scores. Our sample was almost exclusively of prescribers working in the private sector, which may have important differences from the public sector in SA; in particular, remuneration of private prescribers is often determined by patient numbers, which may introduce a motivation to adhere to patient expectations in order to encourage return visits. A large proportion of antibiotic prescribers in the public sector are nurses, and our sample size of nurse prescribers is too small to draw accurate conclusions about this group. Social desirability bias could be introduced, as the accuracy of answers could not be assessed because they are self-reported, but this was minimised as the surveys were anonymous. Further research using alternative sampling methods is needed to remove the effects of these biases and confounders.

\section{Conclusions}

Our study demonstrates gaps in prescriber knowledge that are associated with potentially harmful perceptions and prescribing behaviours. These associations, together with our finding that prescribers would like more education on ABR, suggest that educational tools and patient-provider communication tools could promote rational antibiotic use.

Acknowledgements. The authors thank the Federation of Infectious Diseases Societies of Southern Africa (FIDSSA) and GlaxoSmithKline (GSK) for their support of this project.

Author contributions. EF: first author, substantial contribution to analysis and interpretation of data and the drafting of important scientific content; AS: supervisor, substantial contribution to the analysis and interpretation of data and the drafting of important scientific content; M-AD: supervisor, substantial contribution to analysis and interpretation of data and the drafting of important scientific content; MG: substantial contribution to data collection and approved the final manuscript; DvdB: substantial contribution to data collection and approved the final manuscript; THB: supervisor, substantial contribution to conceptualisation, design, analysis and interpretation of data and the drafting of important scientific content. Funding. This work was supported by an unrestricted grant from the FIDSSA and GSK. The funders played no role in the design, conduct or reporting of the study.

Conflicts of interest. None.

1. O'Neill J. Review on Antimicrobial Resistance. Tackling drug-resistant infections globally: Final report and recommendations. 2016. https://amr-review.org/ (accessed 6 March 2017).

2. Kapi A. The evolving threat of antimicrobial resistance: Options for action. Indian J Med Res 2014;139(1):182-183. http://www.ijmr.org.in/article.asp? issn=0971-5916;year=2014; volume=139;issu $\mathrm{e}=1$;spage=182; epage= $=183$; aulast=Kapi (accessed 1 August 2016).

3. Arnold SSS. Interventions to improve antibiotic prescribing practices in ambulatory care (Review) Cochrane Database Syst Rev 2005, Issue 4. Art. No.: CD003539. https://doi.org/10.1002/14651858. CD003539.pub2

4. Baur D, Gladstone BP, Burkert F, et al. Effect of antibiotic stewardship on the incidence of infection and colonisation with antibiotic-resistant bacteria and Clostridium difficile infection: A systematic review. Lancet Infect Dis 2017;17(9):990-1001. https://doi.org/10.1016/S1473-3099(17)30325-0

5. Michie S, Johnston M, Abraham C, Lawton R, Parker D, Walker A. Making psychological theory useful for implementing evidence based practice: A consensus approach. Qual Saf Health Care 2005;14(1):2633. https://doi.org/10.1136/qshc.2004.011155

6. Tonkin-Crine S, Yardley L, Little P. Antibiotic prescribing for acute respiratory tract infections in primary care: A systematic review and meta-ethnography. J Antimicrob Chemother 2011;66(10):2215-
pritections in primary care: A systematic review and meta-e
2223. https://doi.org/10.1093/jac/dkr279

7. McCullough AR, Rathbone J, Parekh S, Hoffmann TC, del Mar CB. Not in my backyard: A systematic review of clinicians' knowledge and beliefs about antibiotic resistance. J Antimicrob Chemother 2015;70(9):2465-2473. https://doi.org/10.1093/jac/dkv164

8. Brinsley KJ, Sinkowitz-Cochran RL, Cardo DM. Assessing motivation for physicians to prevent antimicrobial resistance in hospitalized children using the Health Belief Model as a framework. Am Infect Control 2005;33(3):175-181. https://doi.org/10.1016/j.ajic.2004.12.004

9. Hardy-Holbrook R, Aristidi S, Chandnani V, Dewindt D, Dinh K. Antibiotic resistance and prescribing in Australia: Current attitudes and practice of GPs. Healthcare Infect 2013;18(4):147-151. https://doi. org/10.1071/HI13019

10. Butler CC, Rollnick S, Pill R, Maggs-Rapport F, Stott N. Understanding the culture of prescribing: Qualitative study of general practitioners' and patients' perceptions of antibiotics for sore throats. BMJ Qualitative study of general practitioners' and patients' percep
1998;317:637-642. https://doi.org/10.1136/bmj.317.7159.637

11. Hoffman D, Botha J. An assessment of factors influencing the prescribing of antibiotics in acute respiratory illness: A questionnaire study. S Afr Fam Pract 2003;45(6):20-24. https://www.ajol.info/
restics respiratory illness: A questionnaire study. S Afr Fam Pract 2003
index.php/safp/article/view/13083 (accessed 6 August 2018).

12. Wasserman S, Potgieter S, Shoul E, et al. South African medical students' perceptions and knowledge about antibiotic resistance and appropriate prescribing: Are we providing adequate training to futur prescribers? S Afr Med J 2017;107(5):405-410. https://doi.org/10.7196/SAMJ.2017.v107i5.12370.

13. Huttner B, Goossens H, Verheij T, Harbarth S. Characteristics and outcomes of public campaigns aimed at improving the use of antibiotics in outpatients in high-income countries. Lancet Infect Dis 2010;10(1):17-31. https://doi.org/10.1016/S1473-3099(09)70305-6

Accepted 3 April 2018. 


\section{Appendix 1. Knowledge, attitudes and perceptions of antibiotic use among prescribers in South Africa}

Where do you practise?

\begin{tabular}{|l|l|l|l|}
\hline Private sector & Public sector & Both, mostly private & Both, mostly public \\
\hline
\end{tabular}

\section{Nurse or doctor}

\begin{tabular}{|l|l|}
\hline Doctor & Nurse \\
\hline
\end{tabular}

Your age
\begin{tabular}{|l|l|l|l|l|}
\hline$<25$ & $25-35$ & $35-45$ & $45-55$ & $>55$ \\
\hline
\end{tabular}

Approximately how many patient consultations do you perform per day

\begin{tabular}{|l|l|l|l|l|}
\hline$<5$ & $5-9$ & $10-14$ & $15-24$ & $>25$ \\
\hline
\end{tabular}

\section{Perceptions and attitudes}

1. How much do you agree with the following statements (agree/disagree/unsure):

a. Antibiotics are overused in South Africa

b. Antibiotic resistance is a significant problem in South Africa

c. New antibiotics are available to deal with the problem of resistance

d. Inappropriate use of antibiotics drives antibiotic resistance

e. Better use of antibiotics will reduce levels of antibiotic resistance

f. Use of broad-spectrum antibiotics when equally effective narrower-spectrum antibiotics are available can increase antibiotic resistance

g. Patients not finishing their course of antibiotics drives resistance

h. Lack of hand disinfection by healthcare workers causes the spread of antibiotic resistance

i. A good knowledge of antibiotics is important to my work as a doctor

j. I would like more education on the appropriate use of antibiotics

k. I feel confident to prescribe antibiotics appropriately

l. I feel pressure from patients to prescribe antibiotics

2. How often do you use the following resources to guide you antibiotic prescribing? (often/sometimes/never)
a. Textbooks
b. Medical journals
c. International/national/provincial/institutional guidelines
d. Tablet or smartphone apps
e. Consultation with colleagues
f. Consultation with specialists in microbiology/infectious diseases
g. Pharmaceutical representative

3. How much do you agree with the following statements? I would value the following resources to improve my antibiotic prescribing (agree/disagree/unsure)
a. Interactive internet-based courses
b. Clearer guidelines for tablet or smartphone apps
c. Clearer guidelines in written form
d. Weekend courses by specialists
e. Weekend courses by general practitioners
f. Better access to diagnostic tests such as point-of-care CRP
g. More resources to educate patients
h. More data on local antimicrobial resistance 
4. If a patient expects an antibiotic but you don't think it's absolutely necessary, how often do you prescribe them?
a. Very often
$>90 \%$
b. Often
$>70 \%$
c. About half the time
$50 \%$
d. Rarely
$<30 \%$
e. Almost never
$<10 \%$

5. If you prescribe antibiotics that are not absolutely necessary, what are some of the reasons? (multiple answers allowed)

a. The patient expects an antibiotic

b. Antibiotics don't need to be absolutely necessary, I just need to think they may help the patient

c. Antibiotics can't harm the patient if they aren't needed

d. Patients can't afford laboratory tests

e. I'm concerned about malpractice claims

f. Not applicable - I only prescribe antibiotics when absolutely necessary

6. How often do you think other doctors prescribe antibiotics when they aren't absolutely necessary?
a. Very often
$>90 \%$
b. Often
$>70 \%$
c. About half the time
$50 \%$
d. Rarely
$<30 \%$
e. Almost never
$<10 \%$

7. When the patient has an infection but antibiotics are not indicated, how often do you use the following strategies (often/sometimes/never)?

a. Explain that the patient has a virus and antibiotics will not help

b. Explain that antibiotics have side-effects that could make them feel worse

c. Explain what to expect in terms of symptom resolution

d. Explain features which, if they develop, should prompt them to seek further medical assistance

e. Give written information about why antibiotics would not help and may cause harm

f. Give written information about what to expect in terms of symptom resolution

g. Explain the need for follow-up if symptoms don't improve

h. Prescribe symptomatic relief

i. Give a delayed prescription for antibiotics (a prescription that can only be collected after a few days if the patient isn't better)

j. Prescribe antibiotics anyway 


\section{Knowledge}

8. A 30-year-old female patient with no significant past medical history asks you to prescribe an antibiotic. She has had a cough productive of green sputum for 1 week following an upper respiratory tract infection. The vital signs and examination of the chest are normal. What is the correct course of action?
a. Prescribe an antibiotic for community-acquired pneumonia
b. Give symptomatic treatment, advice, and information about the condition
c. Prescribe an antibiotic for bronchitis
d. Refer the patient to hospital
e. Investigate for tuberculosis

9. A 35-year-old man who has well-controlled HIV (CD4+ count 360 cells $/ \mu \mathrm{L}$ and viral load $<50$ copies $/ \mathrm{mL}$ ) has been coughing for 2 weeks. He was given 5 days of co-amoxiclav which has not helped. He has been feeling a little feverish and sweaty, but examination is unremarkable. What is your preferred strategy?
a. Reassure him that he has a viral infection that will resolve spontaneously
b. Prescribe a second course of co-amoxiclav
c. Prescribe moxifloxacin to cover atypical/resistant respiratory pathogens
d. Prescribe azithromycin to cover atypical/resistant respiratory pathogens
e. Test sputum for tuberculosis

10. A 66-year-old man who is hypertensive with mild chronic renal impairment has been feeling 'under the weather' for 2 weeks. He is coughing and producing green sputum. His respiratory rate is $32 \mathrm{breaths} / \mathrm{min}$ and his blood pressure 100/55 mmHg. There is bronchial breathing with crepitations in the left lower zone. What is your preferred course of action?
a. Refer immediately to hospital with likely diagnosis of pneumonia
b. Test sputum for tuberculosis
c. Prescribe co-amoxiclav orally and plan to review in a few days
d. Prescribe moxifloxacin orally and plan to review in a few days
e. Give bronchodilators in your clinic and see how he responds

11. A 20-year-old woman is complaining of mild suprapubic pain for 2 days. She is not pregnant. Urine dipstick shows protein 1+, blood neg., leucocyte esterase neg., nitrites neg. What is your preferred course of action?
a. Send a urine sample for microscopy, culture and sensitivity and prescribe an antibiotic for uncomplicated cystitis
b. Prescribe an antibiotic for uncomplicated cystitis
c. Consider urinary tract infection unlikely and look for alternative causes of proteinuria and suprapubic pain
d. Prescribe an antibiotic for uncomplicated cystitis and investigate reasons for protein and blood in the urine
e. Refer to hospital immediately for pyelonephritis

12. A 30-year-old man has had a sore throat and runny nose for 5 days but is otherwise well. His oropharynx is inflamed; there is no exudate on the tonsils and no tender cervical adenopathy. He asks for and antibiotic for 'Strep throat'. What is your preferred course of action?
a. Give advice about symptomatic treatments and information about expected duration of illness
b. Investigate for diphtheria
c. Prescribe penicillin VK
d. Investigate for acute Epstein-Barr virus infection (glandular fever)
e. Prescribe amoxicillin 
13. A 25-year-old woman presented with a urinary tract infection last week, and your colleague prescribed ciprofloxacin as a single dose and sent a urine sample which shows E. coli resistant to ciprofloxacin and sensitive to co-amoxiclav, gentamicin and ertapenem. She has returned as she still has dysuria, but she is no worse. What would be your preferred course of action?

a. Refer to hospital for treatment of this resistant organism

b. Prescribe ciprofloxacin for 3 days

c. Prescribe co-amoxiclav for 3 - 5 days

d. Prescribe oral gentamycin for 3 days

e. Repeat the urine sample

14. A 40-year-old woman has had 3 days of profuse watery diarrhoea up to 8 times per day. There is no blood or mucus and no one else in the family is unwell. She is not clinically dehydrated. What would be your preferred course of action?

a. Prescribe oral rehydration solution and antidiarrhoeal medication

b. Send stool for microscopy, culture and sensitivity and await results

c. Prescribe metronidazole orally

d. Prescribe ciprofloxacin orally

e. Prescribe ciprofloxacin and metronidazole orally 